\title{
JIPES
} Journal of Indonesian Physical Education and Sport

P-ISSN 2442-4900 | E-ISSN 2461-1271

Vol. 6, No.2, December 2020, page 19-25

\section{SELF-EFFICACY SCALE VALIDATION AMONG FOOTBALL PLAYERS}

\author{
${ }^{1}$ Mouloud Kenioua, ${ }^{2}$ Nawal Krine. \\ ${ }^{1}$ Institute of Physical Education and Sport University of Ouargla, Algeria \\ ${ }^{2}$ Faculty of Literature and Language University of Ouargla, Algeria \\ *Corresponding author: moukenioua@gmail.com
}

\begin{abstract}
The purpose of this study was to adapt the Algerian football players of general self-efficacy scale (GSES) developed by Schwarzer \& Jerusalem (1995) which were adapted into more than thirty-three languages. The study conducted on a total of 216 male football players, ranging in age from 15-18 years. After translating the scale according to the local language, it was presented to specialists in psychology and sports psychology to formulate it to suit the applied category. the principal components analysis with varimax rotation was used for the construct validity. The results indicated that there are two-factor structure, the two factors together explained $54.5 \%$ of the total variance. The reliability scales were found by Alpha Cronbach coefficient (0.79). These results confirmed that the self-efficacy scale among football players valid and reliable. It is necessary to conduct future studies in the local culture and on different sports and ages.
\end{abstract}

Keywords: self-efficacy, self-efficacy scale, football players.

\section{INTRODUCTION}

Albert Bandura is the first psychologist to address the subject of self-efficacy, where Bandura (1977) developed the theory of self-efficacy within the framework of social cognitive theory, and this theory was originally developed to find ways and methods in the field of clinical psychology to address anxiety, but it has been incorporated into other psychological fields such as behavior, health and physical activities(McAuley,1992;McAuley\&Mihalko,1998; O'Leary,1982), as well as sports performance (1988). Bandura (1986) indicated that an individual's performance can be explained by an interview of behavior and various cognitive and personal factors.

The concept of self-efficacy is described as Bandura (1982) indicating that it is an influential nature and capable of interpreting the behavior necessary to understand the interaction of individuals with their environments and to build the relationship between knowledge and behavior. Decamps (2012) defined self-efficacy as "the strength of decision, the amount of effort and level of persistence of an athlete to confront obstacles and adversity during training and athletic competitions. Bandura (1977) pointed out that self-efficacy beliefs consist of four sources: mastery experiences, vicarious experiences, verbal persuasion, physiological \& emotional states. 


\section{JIPES}

These four sources can enhance self-efficacy, as well as reduce them. For example, ice hockey players sitting on the bench by watching their colleagues achieve positive results against the competitor can increase their self-efficacy, but in return if they see their colleagues face difficulties, it is possible to reduce their self-efficacy, these sources are not automatic, and each source interferes on time when the athlete wants to explain a performance or task in specific circumstances (Tod,2014). The most influencing source of self-efficacy is the mastery experiences that make the individual able to overcome various obstacles through effort and perseverance; as beliefs of their self-efficacy are enhanced while the experiences of failure reduce them (Bandura, 1997; Maddux,1995). In the sports field, repeated successes in specific tasks enhance the athlete's confidence in his skills and abilities in general (Gernigon \& Delloye,2003). The second source of self-efficacy is vicarious experiences or observational learning through modeling (Feltz, et al.,1979). During observational learning (watching individuals perform certain tasks), the individual tries to estimate the relevant skills that he uses in performing a particular task, as well as trying to deduce the amount of effort that will be required to reach the same (Gist \& Mitchell,1992). In the sport field modeling is a very important way to learn and practice motor skills (Hall et al.20098; SooHoo et al.,2004) and has been shown to enhance the self-efficacy of athletes (McAuley,1985). Verbal persuasion is the third source of expectations for self-efficacy, which indicates the importance of encouragement and verbal rewards (such as: verbal praise, feedback ...), and some sports psychology research has indicated the role of positive feedback from coaches that increase athletes' confidence in themselves, Thus improving performance and vice versa for negative feedback that reduces the level of self-efficacy among athletes ( Villani et all.,2015). Bandura (1982) indicated that verbal persuasion means speech that relates to specific experiences of others and persuasion by the individual or information that comes verbally to the individual through others in what may gain him a kind of motivation in performance and action and affects the behavior of a person while trying to perform a task. Physiological and emotional states, such as tension, anxiety, and fatigue are factors that reduce athlete's performance (Bandura,1977; Bandura,1986; Crain,2000). Therefore, various emotions such as anxiety, as well as levels of physiological arousal, must be adjusted to enhance self-efficacy(Mamassis \& Doganis,2004) .Research in sports psychology also indicated the need to educate and train athletes on various competition conditions, which cause various emotions, so that they have a high self-efficacy that enables them to deal with those events (competitions) in the appropriate manner ( Uphill etal.,2008) .

The first version (German version) of General Self-Efficacy Scale (GSES) was developed in 1979 by Jerusalem and Schwarzer. The original 20-item scale was reduced to 10 items in 1981 and is now available in 33 languages (Schwarzer\& Jerusalem,1995). The construct of perceived self-efficacy gives an optimistic self-belief, this is the belief that one can perform a task, or cope with the critical times in various domains. Perceived selfefficacy helps underline goals, invest in efforts, and persevere in facing obstacles (Schwarzer,1992). The scale is designed for all adults and includes teens as well. Persons below the age of 12 should not be tested (Rimm\& Jerusalem,1999). As other cultures the 
General Self-Efficacy Scale (GSES) has been validated to Arab version (Crandall et al.,2015; Scholz et al.,2002).

Understanding and knowing the self-efficacy is necessary for the sports coach, through which the coach can know the way the player thinks and his future expectations for his skills and abilities and thus can improve and develop them in an appropriate manner according to training and competitive conditions, as well as for the player, his knowledge of his self-efficacy enables him to improve his performance and achieve good results (Moritz et al.,2000). The current study aims to adapt to the General Self-Efficacy Scale to football players. Until now, no study in the local culture touched on this topic according to the limits of the researcher's knowledge. For the purpose of this study, the research study hypotheses are as follows:

HYP.1 The footballers' self-efficacy scale is valid in local culture.

HYP.1 Alpha Cronbach coefficient is high for the self-efficacy scale.

\section{METHOD}

\section{Participants}

The participants were 216 male football players, ranging in age from 15-18 years. The football players came from the teams of Ouargla and Tougourt are active in the regional championship during the 2019/2020 football season. The players were also distributed according to the playing position goalkeeper, defender, midfield, striker (table 1).

Table .1 Disruption of the sample group consistent with their demographic characteristics

\begin{tabular}{lcc}
\hline \multicolumn{1}{c}{ Demographic Characteristics } & $\mathrm{N}$ & $\%$ \\
\hline Age (year) & & \\
15 & 55 & 25.5 \\
16 & 51 & 23.6 \\
17 & 53 & 24.5 \\
18 & 57 & 26.4 \\
Playing position & & \\
Striker & 75 & 34.7 \\
Midfielder & 47 & 21.8 \\
Defender & 64 & 29.6 \\
goalkeeper & 30 & 13.9 \\
Total & 216 & 100 \\
\hline
\end{tabular}

\section{Instrument}

The General Self-Efficacy Scale (GSES) contains 10 items ( 1- I can always manage to solve difficult problems if I try hard enough......10- I can usually handle whatever comes my way), rated on Likert type scale of 1 (not at all true) to 4 (exactly true) (Schwarzer\& Jerusalem,1995). Scale reliability levels were high in all cultures in which it was applied, Alpha Cronbach ranged from 0.76 to 0.90 with a one-dimensional scale (Scholz et 


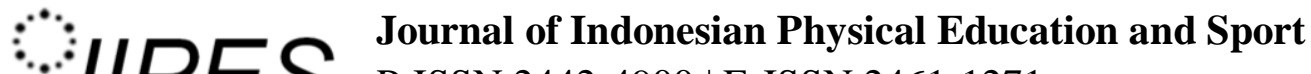 \\ P-ISSN 2442-4900 | E-ISSN 2461-1271 \\ Vol. 6, No.2, December 2020, page 19-25}

al.,2002).After translating the scale according to the local language, it was presented to specialists in psychology and sports psychology to formulate it to suit the applied category ( 1- I can always solve difficult problems during training or competition.......10- Usually, I can face whatever gets in my way during training or competition and have stubborn ideas).

\section{Statistical Tools}

Factor analysis, Correlation and Regression analyses were used to test the hypotheses. SPSS (version 26) was used to interpret the data.

\section{RESULTS AND DISCUSSION}

Table (02) shows the most important results of the Factor Analysis represented by Rotated Component Matrix, the Eigenvalues Factor Analysis was 1.2 the goal is to improve factors strength. Two factors were extracted when the rotation converged in their iterations. The first factor explained $18.84 \%$ of the total variance while the second factor explained $34.70 \%$ of the variance. The two factors together explained $54.5 \%$ of the total variance. the items $1,4,8,5,7$ were saturated on the first factor, the other items $6,3,9,2,10$ were saturated on the second factor. In the table (03) The KMO was 0.670 indicating a high level and Bartlett's test for sphericity was significant $\left(\chi^{2}=183.018\right.$, sig $\left.=0.000\right)$. The Measure of Sampling Adequacy (MSA) was found to be above 0.60 .

Table .2 Rotated Component Matrix

Item

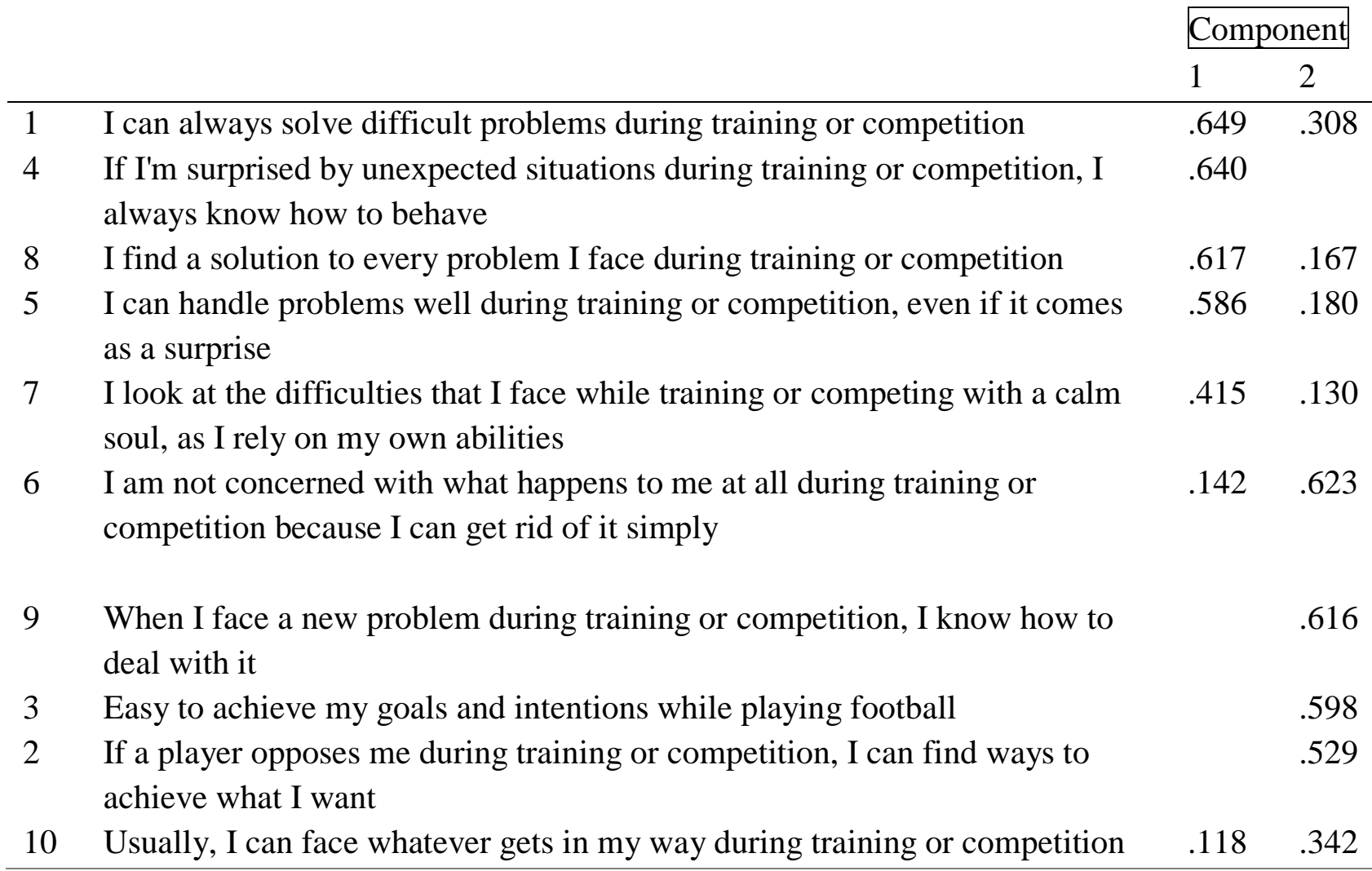




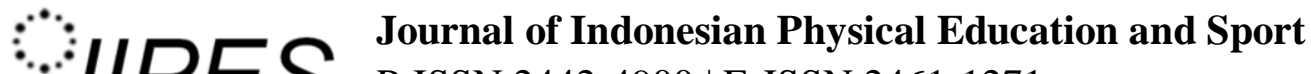 \\ P-ISSN 2442-4900 | E-ISSN 2461-1271 \\ Vol. 6, No.2, December 2020, page 19-25}

and have stubborn ideas

\begin{tabular}{ccc} 
Table .3 KMO and Bartlett's Test \\
\hline \multicolumn{3}{c}{ KMO and Bartlett's Test } \\
\hline Kaiser-Meyer-Olkin Measure of Sampling \\
Adequacy. \\
Bartlett's Test of & Approx. Chi-Square & 183.018 \\
Sphericity & df & 45 \\
& Sig. & .000 \\
\hline
\end{tabular}

The reliability of the scale was also confirmed in the current study, the value of the Alpha Cronbach coefficient was 0.79 (the first factor 0.80 and the second factor 0.77 ).

\section{DISCUSSION}

The results of the current study showed that there are two dimensions of the selfefficacy scale among soccer players. The first dimension is effort and resistance (items:1,4,5,7,8), and the second dimension is willingness and confidence $(2,3,6,9,10)$. The results were different from the results of studies conducted in the Arab culture in Qatar and Syria (Crandall et al.,2015; Scholz et al.,2002). The results indicated that the general selfefficacy scale is one-dimensional. Also, western studies have confirmed that the general selfefficacy scale is unidimensional (Cheung\&Sun,1999; Leung\& Leung,2011; Schwarzer et al.,1997; Teo\& Kam, 2014; Zhang\& Schwarzer, 1995). On the other hand, the results of the current study were consistent with some studies conducted in Asia, the results study of Chiu \& Tsang (2004) showed that exploratory factor analysis yielded a two-factor which was different from overseas studies which showed the scale to be unidimensional. In a study by Zhou (2016) that aimed to re-examine its factor structure in a Chinese context, findings indicated that the two-factor structure was reliable. As well as the results study of Aypay (2010) that was conducted in Turkish culture and confirmed that the general self-efficacy scale contains two dimensions (effort dimension and confidence dimension).

\section{CONCLUSION}

Through the above, the validity of self-efficacy scale among football players (15-18 years) was confirmed, it is a scale that contains two dimensions, the first dimension is effort and resistance, while the second dimension represents willingness and confidence. The results of the current study conflicted with previous studies and were consistent with other studies. Therefore, it is necessary to conduct future studies in the local culture and on different sports and ages. 


\section{$\because .010-8$ Journal of Indonesian Physical Education and Sport \\ P-ISSN 2442-4900 | E-ISSN 2461-1271 \\ Vol. 6, No.2, December 2020, page 19-25}

\section{REFERENCES}

Bandura, A. Self-efficacy: Toward, A unifying theory of behavior change. Journal of Psychological Review, 1977; 184(2), 191-215. https://doi.org/10.1037/0033-295X.84.2.191

McAuley, E. Self-referent thought in sport and physical activity. In T. S. Horn (ed.), Advances in Sport Psychology, (pp. 101-118). Champaign, IL: Human Kinetics;1992.

McAuley, E., \& Mihalko, S. L. Measuring exercise-related self-efficacy. In J. L.Duda (Ed.), Advancements in sport and exercise psychology measurement (pp. 371-390).Morgantown, WV: Fitness Information Technology;1998.

O'Leary, A. Self-efficacy and health. Behavior research and therapy, 1982;23(4), 437-451. DOI:10.1016/0005-7967(85)90172-x

Feltz DL. Self-confidence and sports performance. In K. B. Pandolf (Ed.) Exercise and Sport Sciences Reviews, (pp. 423-457). New York: MacMillan ;1988.

Bandura, A. Social foundations of thought and action: a social cognitive theory. Englewood Cliffs, N.J.: Prentice-Hall;1986.

Bandura, A. Self-efficacy mechanism in human agency. Journal of American psychology,1982 ; 37(2),122-147. https://doi.org/10.1037/0003-066X.37.2.122

Decamps ,G . Sport psychology and performance (1st Ed). Brussels: Boeck Group S.A.2012.

Tod,DSport psychology. The basics. (1 st Ed), New York: Routledg. 2014.

Bandura, A. Self-efficacy. The exercise of control. New York: W.H.Freeman.1997.

Maddux, J. Self-efficacy theory: An introduction. In J. Maddux. (Ed.), Self-efficacy adaptation and adjustment: Theory research and application (pp. 3-33). New York, NY: Plenum Press.1995.

Gernigon, C., \& Delloye, J. Self-efficacy, causal attribution, and track athletic performance following unexpected success or failure among elite sprinters. Sport Psychologist,2003; 17, 55-76. https://psycnet.apa.org/record/2003-02630-005

Feltz, D. L., Landers, D. M., \& Raeder, U. Enhancing self-efficacy in high-avoidance motor tasks: a comparison of modeling techniques. Journal of Sport and Exercise Psychology,1979; 1, 112122.

Gist, M., \& Mitchell, T. Self-efficacy: A theoretical analysis of its determinants and malleability. Academy of Management Review,1992; 17, 183-211. doi:10.5465/AMR.1992.4279530.

Hall, C. R., Munroe-Chandler, K. J., Cumming, J., Law, B., Ramsey, R., \& Murphy, L. Imagery and observational learning use and their relationship to sport confidence. Journal of Sport Sciences,2009; 27, 327-337. Doi: 10.1080/02640410802549769.

SooHoo, S., Takemoto, K., \& McCullagh, P. A comparison of modeling and imagery on the performance of a motor skill. Journal of Sport Behavior,2004; 27, 349-366. https://psycnet.apa.org/record/2004-21135-004

McAuley, E. Modelling and self-efficacy: A test of Bandura's model. Journal of Sport Psychology, 1985 ;

7,283-295. https://journals.humankinetics.com/view/journals/jsep/7/3/article-p283.xml

Villani, D., Caputo, M., Balzarotti, S., \& Riva, G. Enhancing self-efficacy through a blended training: A pilot study with basketball players. International Journal of Sport and Exercise Psychology,2015 ; 15(2), 160-175. https://doi.org/10.1080/1612197X.2015.1079921

Crain, W. Theories of development: Concepts and applications. (4th Ed.). London: PrenticeHall.2000. 


\section{JIPES}

Journal of Indonesian Physical Education and Sport P-ISSN 2442-4900 | E-ISSN 2461-1271

Vol. 6, No.2, December 2020, page 19-25

Mamassis, G., \& Doganis, G. The effects of a mental training program on junior's pre- competitive anxiety, self-confidence and tennis performance. Journal of Applied Sport Psychology,2004; 16, 118-137. doi:10.1080/10413200490437903 .

Uphill, M. A., McCarthy, P. J., \& Jones, M. V. Getting a grip on emotion regulation in sport: Conceptual foundations and practical applications. In S. M. S. Hanton (Ed.), Advances in applied sport psychology: A review (pp. 162-194). Abingdon: Routledge.2008.

Schwarzer, R., \& Jerusalem, M. Generalized Self-Efficacy scale. In J. Weinman, S. Wright, \& M. Johnston, Measures in health psychology: A user's portfolio. Causal and control beliefs (pp. 35-37). Windsor, UK: NFER-NELSON.1995.

Schwarzer, R. Self-efficacy: Thought control of action. Washington, DC: Hemisphere.1992.

Rimm, H., \& Jerusalem, M. Adaptation and validation of an Estonian version of the General SelfEfficacy Scale (ESES). Anxiety, Stress, and Coping, 1999 ; 12, 329-345. https://doi.org/10.1080/10615809908250481

Crandall, A., Rahim, H. A., \& Yount, K. M. Validation of the general self-efficacy scale among Qatari young women. Eastern Mediterranean Health Journal, 2015 ;21(12), 891-896. DOI:10.26719/2015.21.12.891.

Scholz U, Doña BG, Sud S, \& Schwarzer, R.Is general self-efficacy a universal construct? Psychometric findings from 25 countries.Eur J Psychol Assess.2002;18(3):242-51. DOI: $10.1027 / / 1015-5759.18 .3 .242$

Moritz, S. E., Feltz, D. L., Fahrbach, K. R., \& Mack, D. E. The relation of self-efficacy measures to sport performance: A meta-analytic review. Research quarterly for exercise and sport, $2000 ; 71(3), 280-294$

Cheung, S. K., \& Sun, S. Y. Assessment of optimistic self-beliefs: further validation of the Chinese version of the General Self-Efficacy Scale. Psychological Reports,1999; 85, 1221-1224. https://doi.org/10.2466/pr0.1999.85.3f.1221

Leung, D. P., \& Leung, A. M. Factor structure and gender invariance of the Chinese general selfefficacy scale among soon-to-be-aged adults. Journal of Advanced Nursing, 2011 ;67(6), 1383-1392. https://onlinelibrary.wiley.com/doi/abs/10.1111/j.1365-2648.2010.05529.x

Schwarzer, R., Bäßler, J., Kwiatek, P., Schröder, K., \& Zhang, J. X. The assessment of optimistic selfbeliefs: comparison of the German, Spanish, and Chinese versions of the general selfefficacy scale. Applied Psychology,1997; 46(1), 69-88. https://doi.org/10.1111/j.14640597.1997.tb01096.x

Teo, T., \& Kam, C. A measurement invariance analysis of the general self-efficacy scale on two different cultures. Journal of Psychoeducational Assessment, 32(8),2014 ; 762-767. https://doi.org/10.1177/0734282914531707

Zhang, J. X., \& Schwarzer, R. Measuring optimistic self-beliefs: a Chinese adaptation of the general self-efficacy scale. Psychologia: An International Journal of Psychology in the Orient,1995 ; 38, 174-181. https://psycnet.apa.org/record/1996-35921-001

Chiu, F. P., \& Tsang, H. W. Validation of the Chinese general self-efficacy scale among individuals with schizophrenia in Hong Kong. International Journal of Rehabilitation Research, 27(2),2004; 159-161 10.1097/01.mrr.0000127640.55118.6b

Zhou, M. A revisit of general self-efficacy scale: Uni-or multi-dimensional?. Current Psychology, 35(3),2016 ; 427-436. DOI 10.1007/s12144-015-9311-4

Aypay, A. The Adaptation Study of General Self-Efficacy (GSE) Scale to Turkish. Inonu University Journal of the Faculty of Education (INUJFE), 11(2).2010. 